\title{
El futuro de la tecnología y la tecnología del futuro
}

\section{The future of the technology and the technology of the future}

\author{
José Luis Cordeiro' \\ Disertación en Conferencia Magistral realizada durante el programa académico de aniversario de la \\ Universidad Continental, Huancayo, Perú
}

Vivimos en un mundo centrado en el Pacífico con las dos grandes potencias del futuro que son China e India; el mundo está centrado en el Pacífico aunque todo es relativo. Ustedes deben ver el mundo con una nueva cara, no solo que vean el mundo, sino que vean más allá del mundo y que piensen incluso en el resto del universo.

En los próximos años vamos iniciar finalmente la colonización de Marte. Marte es el planeta más parecido que hay a la Tierra y de hecho se está planteando cómo terraformar Marte, cómo cambiar el ambiente de Marte para que puedan vivir los humanos en los próximos años y hay un grupo de científicos trabajando activamente en esto y no solo con exploración humana sino robótica, y la NASA está trabajando en una misión espacial para las próximas décadas porque se están encontrando muchos planetas en el resto del universo en los cuales se cree que en algunos de ellos hay vida, en las próximas décadas probablemente descubramos algún planeta que tiene vida y esto va a cambiar la concepción misma de la vida en la Tierra.

Estamos viviendo los tiempos más increíbles y no solo en la Tierra sino más allá de la Tierra incluso hay un grupo de peruanos trabajando con lo que se llama la Sociedad Marte para iniciar la colonización de Marte, en estos momentos existen ocho misiones espaciales para ir a Marte, cuatro de ellas son públicas, o sea de gobiernos como Estados Unidos a través de la NASA, Rusia que también tiene una misión, China y la Unión Europea; además de cuatro misiones privadas. Varios peruanos están participando en dos de estas misiones privadas para ir a Marte, de hecho están buscando voluntarios

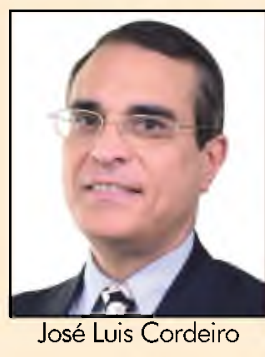

Historial del artículo: Recibido: 02 de agosto de 2014 Aprobado: 9 de octubre de 2014 Disponible en línea: 30 de diciembre de 2014

para ir a dicho planeta.

Se han descubierto muchísimos planetas, muchos de estos son equivalentes a la Tierra y en la NASA con nuevos telescopios espaciales piensan en los próximos años poder ver sus atmosferas para comprobar si tienen presencia de gases que indican la presencia de vida. Vivimos en tiempos realmente interesantes (figura $\mathrm{N}^{\circ} 1$ ). 
Existe un grupo peruano, de hecho el capítulo The Mars Society Perú, donde hay un equipo peruano que va estar trabajando en esta misión espacial y hasta el punto que ya están haciendo simulaciones. Hay un científico peruano Alejandro Díaz que también trabaja en la NASA y él ha logrado hacer un acuerdo para crear fuera de Arequipa un Centro de Simulación de Marte. También en la Universidad Nacional de Ingeniería lanzaron el primer microsatélite espacial y desde entonces dos universidades más lo han hecho, la Universidad Alas Peruanas y la Universidad Católica; esto no cuesta caro, la tecnología ha aumentado a una velocidad tan rápida que hoy se puede hacer estas cosas de una manera muy barata; aparte de esta base que esta fuera de Arequipa financiada parcialmente por la NASA y otros organismos, hay gran interés en Perú por la ciencia; hace cuatro días un joven peruano de 13 años que vive en la zona amazónica del Perú ha ganado el Concurso Internacional de Google en temas científicos entonces vean que los peruanos están marcando la pauta incluso a nivel internacional según el Diario Perú 21 , un tema interesantísimo.

La singularidad tecnológica, es el evento mas trascendente en la historia presente y futuro de la humanidad, nosotros estimamos que esto va a ocurrir entre el año 2029 y 2045; la revista Time publico hace unos meses un artículo titulado "2045: The year man becomes immortal" esto es solo una de las consecuencias de la singularidad tecnológica, lo que viene en los próximos años es realmente ciencia ficción, son avances tan impresionantes que la gente todavía no lo comprende bien.

Hay un científico de Massachusetts Institute of Technology (MIT) llamado Ray Kurzweil quien escribió el libro "The Singularity is Near" donde el habla de la singularidad y de lo que va a ocurrir entre el año 2029 y el 2045, esos son los años cuando nosotros esperamos que va a ocurrir la singularidad tecnológica.

La singularidad tecnológica es el momento cuando la inteligencia artificial alcanza a la inteligencia humana, por ejemplo antes se tenia las tarjetas de $1 \mathrm{kB}$, luego pasamos a una evolución grande con los disquetes de ocho pulgadas, hoy hablamos de grandes volúmenes de almacenamiento en $t B$, estos cambios que ustedes están viendo ocurren en todas las tecnologías, no solo en informática. La gente piensa que solo las computadoras están cambiando, pero no, todas las tecnologías están cambiando; por ejemplo el genoma humano, yo fui el primer

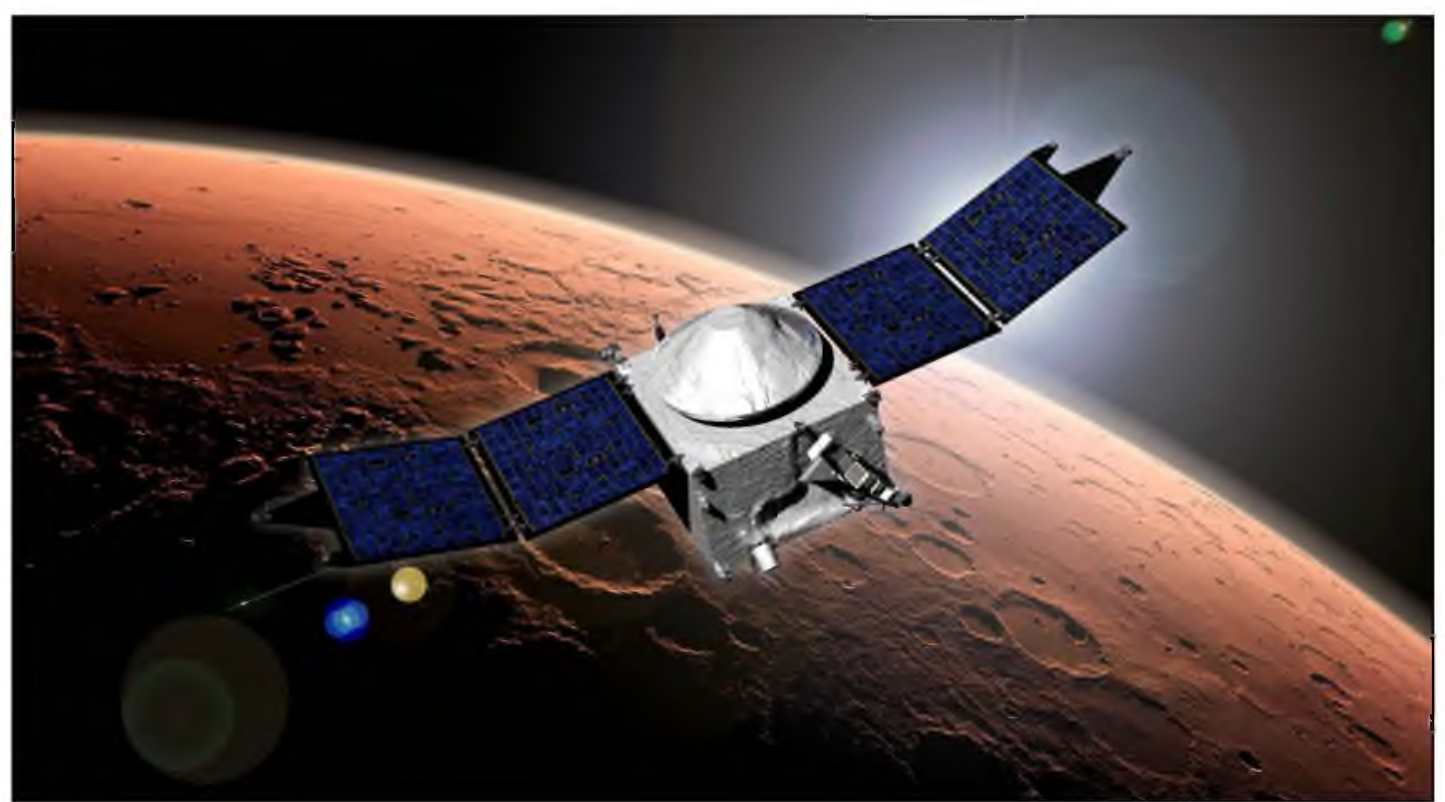

Figura $N^{\circ}$ 1: Nave espacial de la NASA en aproximación a Marte.

Fuente: NASA, http://www.nasa.gov/sites/default/files/maven_mars_sunrise_2.jpg 
venezolano que secuencio su genoma hace cinco años, esta información de mi genoma se encuentra en Internet para hacer análisis médicos, por ejemplo, se muestra todas las enfermedades que yo voy a tener. Con la secuencia del genoma humano en los próximos años todas las personas van a secuenciar su genoma; en menos de diez años las personas van a saber todas las enfermedades que van a tener y esto permitirá prevenir esas enfermedades.

La medicina actual es un arte, la medicina del futuro va ser una ciencia perfecta basada en sus genomas, en los próximos años cuando todas las personas secuencien su genoma, ellos ya no van a curar la enfermedad, ellos van a prevenir la enfermedad. La medicina del futuro no va ser curativa, será una medicina preventiva y no va ser una medicina general va ser una medicina personalizada de acuerdo con las características de cada persona, ustedes también podrán conocer sus características físicas. Cuando ustedes secuencien su genoma van a saber de que color son sus ojos si no lo sabían, adicionalmente podrán saber de dónde vienen sus ancestros, todas las personas van a poder registrar su genoma y van a poder construir su árbol genealógico, ustedes van a poder verificar científicamente si su papá es realmente su papá, pero lo mas interesante es que vamos a construir y diseñar los descendientes como queremos.

El primer genoma humano secuenciado comenzó en el año 1990 y termino en el 2003, tomo 13 años secuenciar el primer genoma humano y costo un billón de dólares, el segundo genoma humano tomó cuatro años y se terminó para el 2007 tuvo un costo de 100 millones de dólares; nosotros esperamos que en diez años el genoma humano se secuencie en un minuto y cueste 10 dólares, todas las personas van a tener un chip y después de un minuto van a saber el color de sus ojos y de qué se van a morir, esto va a transformar totalmente la medicina y muchas otras cosas en los próximos años. Al ver la escala de tiempo y costo, es increíble bajar de 1 billón de dólares a 10 dólares, bajar de trece años a un minuto, si ustedes pensaban que los avances de la informática eran impresionantes esto no es nada comparado con lo que está pasando en biotecnología y en todas las tecnologías vamos a ver estos cambios impresionantes. Todo está cambiando y se esta haciendo cada vez todo más pequeño, más barato y son cambios exponenciales.

La diferencia entre cambios exponenciales y cambios lineales, un ejemplo es que si ustedes dan treinta pasos lineales de un metro cada paso ¿̇Dónde van a estar después de treinta pasos?, van a estar a treinta metros; pero, si ustedes dan treinta pasos exponenciales, 1, 4, 8, 10, 16, 32, etc, después de treinta pasos, ustedes van a dar la vuelta a la tierra 26 veces y esto es muy difícil para comprender porque nosotros pensamos linealmente, la tecnología está cambiando exponencialmente. Todas las tecnologías, biotecnología, infotecnologia, nanotecnología, y estos cambios exponenciales van a transformar la humanidad en los próximos años, todo se esta globalizando estamos pasando de un mundo local a un mundo global.

Por ejemplo Japón es un país chico y pobre en recursos pero con gente rica, mientras que Perú es un país grande y rico pero con gente pobre y żpor qué la diferencia?, porque Japón se ha involucrado muchísimo en ciencia y tecnología y eso es lo importante que un país solo avanza cuando se dedica a la ciencia y tecnología, así como Japón están muchos otros países como Corea del Sur, Hong Kong, entre otros. Si nosotros vemos cuanto tiempo ha tomado duplicar el ingreso per cápita de un país. El primer país que duplico su ingreso per cápita fue el Reino Unido durante la Revolución Industrial entre 1780 y 1838 , es decir a Inglaterra le tomó 58 años para duplicar por primera vez el ingreso de su población; el record mundial lo lleva China, hoy en día cada siete años duplica el ingreso de su población esto es maravilloso, esto demuestra que ya no hay escusas para seguir siendo pobre o subdesarrollado porque hoy sabemos qué funciona y qué no funciona y ahí esta el caso de China que cada siete años duplica el ingreso de su población. 
El negocio no está en la materia prima, está en el valor agregado, incluso en el mercadeo, en la imagen. Los futuristas hablamos de cuatro maneras de ver el futuro: la peor manera es la pasiva como el avestruz, si ustedes no quieren ver el futuro esconden la cabeza y que pase lo que pase; un poco menos malo es ser reactivo como un bombero que interviene cuando hay un fuego, pero mejor todavía ser preactivo como cuando ustedes compran un seguro para preparase ante cualquier problema; pero lo mejor es ser proactivo, crear el futuro que uno quiere prepararse para las cosas que pueden pasar ver escenarios buenos, escenarios malos y como alcanzar los escenarios buenos.

Arthur C. Clarke, autor del libro Las tres leyes del futuro lo escribió hace medio siglo atrás cuando todo era lento y dijo entonces en los años 60: Primera Ley cuando un científico famoso dice que algo es posible probablemente tiene razón, pero cuando dice que todo es imposible probablemente esta equivocado; Segunda Ley la única manera de conocer los límites de lo posible es aventurarse mas halla de ellos hacia lo imposible, y Tercera Ley cualquier tecnología suficientemente avanzada no se diferencia de la magia ósea si ustedes ven una tecnología que no parece magia es por que no es avanzada. Veamos algunas de estas tecnologías: hace treinta años no había computadoras personales; hace veinte años apenas comenzaron los teléfonos celulares, hace diez años Google era una pequeña compañía; bueno i̇que va a ocurrir en los próximos diez años, veinte años, treinta años?, van a ocurrir cosas mágicas cosas que parecen ciencia ficción y que si no parece magia es porque no son avanzadas, una de esas es el control del envejecimiento que se va a curar entre los próximos veinte y treinta años.

Existe una fundación internacional llamada Methuselah Foundation, que está trabajando en hacer que los ratones vivan mil años, todos sabemos que los ratones viven poco, aproximadamente año y medio, entonces uno puede hacer muchos experimentos con muchas vidas ratoniles, esto aun no se puede hacer con vidas humanas por todos los riesgos existentes; hoy ya tienen ratones que viven tres veces su expectativa de vida, o sea ratones que viven cinco años, esto se ha logrado en los últimos diez años; entonces que va a pasar en los próximos diez años, probablemente se van a tener ratones que vivan mil años y después esto se va a utilizar en otras especies, de hecho ya existen mosquitos que viven cuatro veces mas su expectativa de vida o gusanos que viven seis veces mas de su expectativa de vida.

Hoy sabemos que hay dos tipos de células que son inmortales o que no envejecen. Quiero hacer una diferencia entre la inmortalidad y el envejecimiento, lo que se está trabajando es en el control del envejecimiento que no haya envejecimiento, que no es lo mismo que ser inmortal. El primer tipo son las células germinales, que son las células que hacen los espermatozoides y los óvulos, estas células no envejecen; y el segundo tipo de células que no envejecen es el cáncer. El cáncer es una serie de mutaciones que hace que las células dejen de envejecer; las células cancerígenas descubrieron cómo volverse inmortales, entonces żpor qué no podemos hacer inmortales a las células buenas?, la respuesta es que sí lo vamos hacer con las células buenas en los próximos diez, veinte - treinta años a mas tardar, y nosotros vamos a controlar el envejecimiento de las células. Por si fuese poco, Google anunció hace seis meses -a través de la revista Time- que ha creado una nueva compañía para curar la muerte, la compañía se llama Calico; es decir Google resolverá la muerte, yo creo que sí lo va hacer en los próximos años. También acabo de hacer un documental con History Channel denominado Vida eterna. La National Science Foundation (NSF) mencionó hace seis años cuáles son las cuatro tecnologías que van a transformar a los humanos, estas son, la nanotecnología, biotecnología, infotecnologia y cognotecnologia o ciencia cognitiva o neurociencia. La nanotecnología estudia los átomos, la biotecnología estudia las células, la cognotecnologia estudia las neuronas y la infotecnologia estudia los 
bits, yo lo llamo el hardware de la vida al nano y bio; la info y la cogno son el software de la vida entonces tenemos el hardware y el software. En los próximos veinte o treinta años ¿Cómo vamos alcanzar la inmortalidad del hardware y la inmortalidad del software humano?, tanto a nivel de hardware y de software nosotros vamos a ser inmortales.

\section{Complejidad del hardware humano}

Nanotecnología es hacer las cosas átomo a átomo, la nanotecnología comienza con las impresiones 3D y hoy se pueden hacer impresiones cada vez más pequeñas, yo tengo un grupo de estudiantes que están trabajando en California en una compañía que hace impresoras 3D para el espacio, estas están ahora en la estación espacial internacional, pero esto se puede hacer en muchas partes del mundo; también tengo un grupo de estudiantes en Venezuela, en Perú y en la cuenca amazónica, entonces, esto de impresoras 3D se puede hacer en cualquier parte del mundo, como todas las tecnologías comienzan caras pero luego se vuelven baratas, hoy ustedes pueden comprar una impresora 3D por tan solo 300 dólares, eventualmente vamos a llegar a cosas mas chiquitas como un motor de nanotecnología hecho átomo a átomo, con la nanotecnología nada sobra ni nada falta, la nanotecnología es la ingeniería a la perfección, con la nanotecnología no va haber desperdicio y basura, este término basura no va a existir en el vocabulario, lo que va a existir es materia prima en el lugar equivocado y con la nanotecnología ustedes lo van a poner en el lugar correcto, entonces en el futuro las ciudades van a ser limpias, ecológicas y supermodernas.

Biotecnología, que es básicamente la nanotecnología viva, es usar la vida para hacer nuevas cosas. Un grupo de científicos hace diez años creó los primeros peces transgénicos que son unas cebritas brillantes, son las famosas cebras a las cuales les han puesto el gen de la medusa fluorescente y existen en cinco colores. La biología sintética, que es la creación de nuevas formas de vida, hace diez años creó el primer virus artificial, hace tres años se creo la nueva bacteria artificial, en los próximos diez años vamos a ver nuevos organismos cada vez más grandes creados artificialmente.

\section{Complejidad del software humano}

La infotecnologia, todo va estar conectado con todo gracias al Internet. Google anunció hace algunos meses que para el 2020 ellos conectarán el planeta entero con internet gratis con banda ancha, están trabajando con globos, ya han hecho este experimento en dos países, primero en Nueva Zelanda y hace algunos meses en Brasil, estos experimentos son tan exitosos que creen que tal vez no tienen que esperar hasta el 2020, sino 3 ○ 4 años. También Facebook anunció otro proyecto en el cual están trabajando con drones, que también tienen conexión al wifi. Esto va a transformar a la educación y al mundo.

La cognotecnologia, referida al cerebro. El cerebro es el órgano más complejo que existe y por eso es el único órgano que todavía no hemos replicado artificialmente, ya los científicos han hecho sangre artificial, huesos artificiales, páncreas artificiales, corazones artificiales, pulmones artificiales de todo artificial, menos el cerebro, ípor qué?, porque el cerebro es la estructura más compleja, en el universo conocido no hay nada más complejo que el cerebro de un ser humano. En unos años ya se podrá tener cerebros artificiales, actualmente se están haciendo conexiones del cerebro a la computadora, esto internas o externas, de hecho ya existen juegos que se hacen con la conexión al cerebro y tenemos algunos productos como el lector de mente.

Estamos viviendo los tiempos más increíbles en el mundo con una gran oportunidad para aprovecharla. 